\title{
IDENTIFICATION OF THE KEY OPERATIONAL PARAMETERS AS AN ELEMENT OF TECHNOLOGICAL PROCESS' OPERATIONAL CONTROL
}

doi: $\quad 10.2478 /$ czoto-2019-0065

Date of submission of the article to the Editor: 27/11/2018

Date of acceptance of the article by the Editor: $28 / 12 / 2018$

Tatiana Karkoszka - orcid id: 0000-0002-7853-3654

Silesian University of Technology, Poland, tatiana.karkoszka@polsl.pl

Abstract: Assurance of the supervised conditions in all processes affects directly both products and users safety and environmental influence. ISO 9001 and ISO 14001 standards in Operation point require from organisations to implement and control the planned processes by establishing processes' criteria, assuring the supervised conditions and verifying processes' conformity. Moreover, in Planning section it is required to plan the processes with the consideration of quality and environmental risk. Therefore research on the practical solutions of operational planning and control in the production processes are of the crucial meaning, especially from the perspective of the integrated fulfilment of the requirements. That is why the value of the paper is being constituted by the authorial methodology of identification of the key-operational criteria, including integrated risk assessment, using the computer support and being a starting point for assurance of the supervised conditions in the key-processes of high risk. The worked out methodology has been implemented in the processes of performance and completing the stirrups, which quality is of the huge influence on the work safety of the mine roadway supports in the mine workings. The aim of the analysis was to identify the operational parameters in the stirrups technological process, to estimate their meaning and to point at the key operational criteria from the point of fulfilling the quality and environmental requirements. Practical implication of the proposed methodology can be applied in case of any organisation which wants to improve the realised processes ensuring the computer supported supervised conditions.

Keywords: quality requirements, environmental protection, operational control, operational criteria, computer support

\section{INTRODUCTION}

The stirrups are used to link the elements of the roadway supports in the underground mine workings. Their functioning should guarantee the proper force of compression between the co-operating profiles, which has the direct influence on the work of the following elements: friction joint, friction stands and doorframes - and finally on the whole mine roadway support. The work of the stirrups plays, therefore, a key role in 
the safe functioning of the mine road-way supports, however, in the opinion of the users - it represents the weakest element. In such a situation, of high significance is the proper performance and completion of the stirrups (Brodny, 2011, 2013, 2015).

In the view of the constantly rising requirements both the defect-free products ensuring the safe usage and the technological processes realised with the rules of the sustainable development are of the huge significance (Rocha et al., 2007).

Therefore, it is vital that the stirrups' technological processes are implemented into the integrated quality and environmental management system. The systemic solutions aim at the systemization of all operations realised within the scope of technological process as well as the assurance of conformity among planned and obtained technological and technical parameters. However, one should take into consideration that fulfilment of the quality requirements and minimizing the environmental impact both are realised especially on the operational level of each organisation (Karapetrovic et al., 2006; Bernardo et al., 2009; Karkoszka, 2017).

The management system, in each of the organisations, is directed at the realisation of the planned aims in the same way no matter which these aims concern. Currently, the most popular management systems cover: quality management system and environmental management system (ISO Survey, 2017). Implementation of these systems allows for formalisation, in the basic range, the activities which should ensure the fulfilment of the requirements represented by the clients and all interested parties (Jørgensen et al., 2006; Esquer-Peralta et al., 2008). Nevertheless, the published research results unequivocally confirm that the organisations integrating the management systems face the problems concerning the full integration within this operational range (Karapetrovic et al., 2006; Bernardo et al., 2009; Karapetrovic et al., 2010; Bernardo et al., 2011; Simon et al., 2011).

Therefore, it might be stated that the processes aimed at the direct realisation of the tasks concerning the quality and the environment during the realisation of the product remain at the competences of various organisational units, which is often due to the lack of the coherent operational criteria (Karapetrovic et al., 2006; Simon et al., 2011; Labodova, 2004; Asif et al., 2010; Karkoszka, 2017).

Supposedly, the solution of the so-far problems connected with the integration of the management systems is the novelisation of ISO 9001 and ISO 14001 norms, which aims at ensuring the compatibility between the requirements of the particular standards via implementation of the approach based on the risk and the homogenous structure (Karkoszka, 2017).

In the new propositions of the norms traditionally few points are of the general character and refer to these actions of the organisation with which in most cases there is no difficulty if we consider the implementation (ISO 9001, 2015; ISO 14001, 2015). At the operational level, the points concerning Planning and Operation are the most meaningful.

Planning (section 6) includes the requirements connected with planning the processes considering elimination of quality and environmental risk and usage of opportunities in realised processes beginning from identification of the risks, through planning the methods of risks and opportunities addressing, on the assessment of the effects' effectiveness finishing. Every action which are taken to address quality and environmental risks and opportunities should be appropriate to their influence on assurance of the conformity of goods, services, customer satisfaction as well as environmental conformity (ISO 9001, 2015; ISO 14001, 2015). 
Operation (section 8) reflects the realisation of the objectives which have been planned in Planning point. Organisation implements and controls the planned processes by establishing processes' criteria, assuring the supervised conditions and verifying processes' conformity. The only one point, which is similar in the quality and environmental range is Operational planning and control. That point means the implementation of the solutions preventing deviation from the planned quality and environmental objectives. Organisation defines the criteria of the processes and uses control to confirm the conformity of the processes with the specified criteria, what is confirmed in the documentation (ISO 9001, 2015; ISO 14001, 2015).

The requirements of the new standards, unfortunately again, do not reflect in a direct way the operational control in the integrated range. Such requirements, in practice, may only create the possibilities of processes realisation, which ensures minimising the risk connected with appearing of the incompatibilities and environmental influences. Only they point at the duty of planning and realising the operational actions minimising the risk, however, various in distinct systems.

In the context of differential, depending on the range of the operational criteria, the organisations again face the following dilemma: in what way, at the operational level, meet the integrated requirements. Exactly in this range, indispensable are the research pointing the effective ways of management at the operational level in the conditions of the limited possibilities of their integration and the turbulent character of the organisation's activity conditioning - these internal and coming from organisation's surrounding ones.

Improvement of the operational standards should cover defining the optimal work parameters, resources and wear of the technological media, as well as the analyses and documentation of the aberrations from these parameters. Therefore, it is necessary both, searching for the effective method of identification of the key operational criteria and their supervised realisation, as well as works on taking advantage of the computer support within the guarantee of the compatibility of both planned and real operational criteria, which is the subject of the study presented (Karkoszka, 2016; Karkoszka, 2017).

\section{METHODOLOGY}

The aim of the work is improvement of the technological processes of the doubleyokes stirrups by the development and application of the key-parameters-identification method and the computer supportive tool for supervision of the process realisation. The tool in question is the support for operational control with the process and should guarantee the accordance between the key-criteria and operational features and the legal requirements, technical specifications and the other defined requirements.

As the operational criteria one has named the technological parameters of the analysed process, as the operational features one has named the technical parameters of the stirrups together with taking into consideration the influence on the environment. As the key-operational criteria, one has pointed these ones, which due to the high risk, must undergo the operational supervision. The developed procedure of operational control in the stirrups' technological process with computer support has been presented in the Figure 1. 


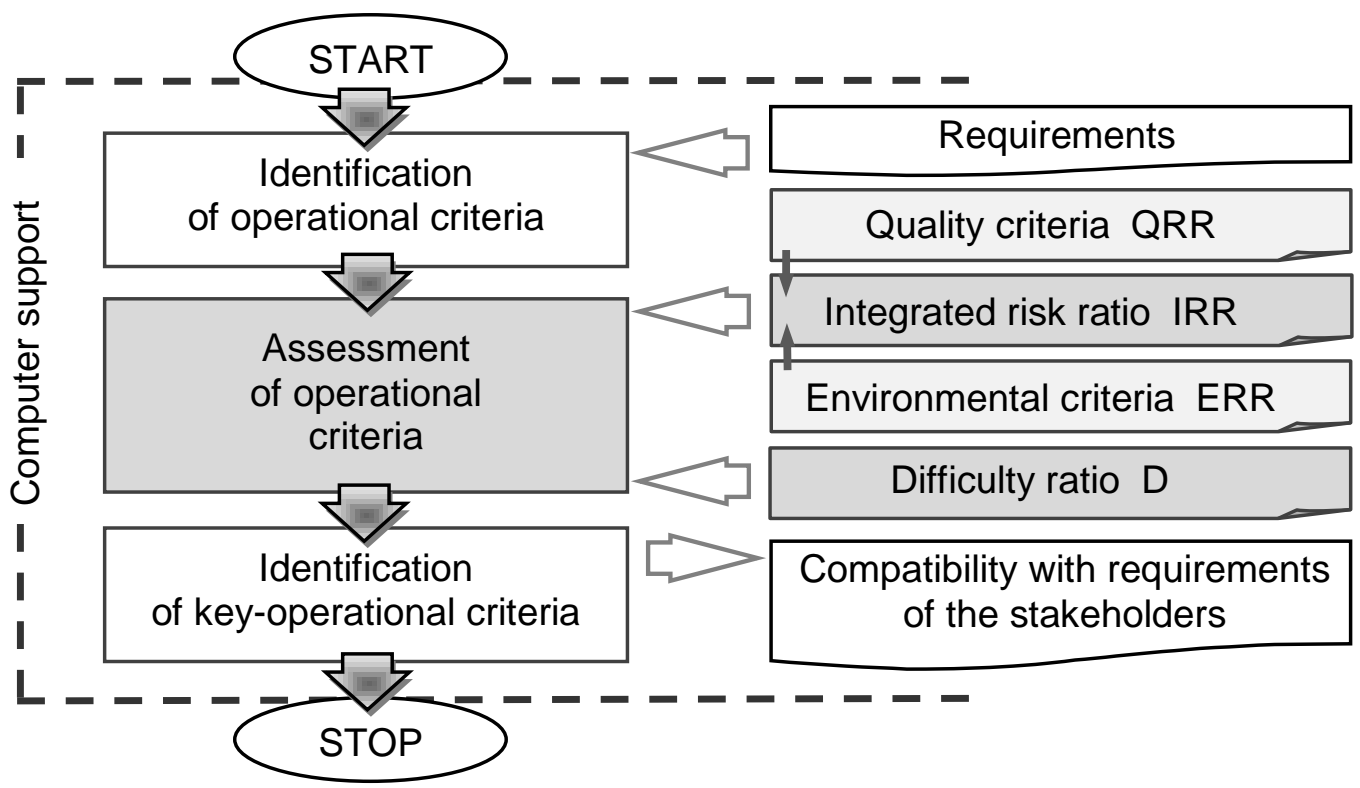

Fig. 1. Procedure of identification of the key-operational criteria

The proposed operational module enables the following: collecting and archiving the data, assessment of the operational risk by appointing the Integrated operational risk ratio (IRR) and the operational criteria realisation Difficulty ratio (D) and defining the critical criteria, which in turn allows for regulation the process ensuring the conformity with the required values of the operational criteria.

Value of the Integrated risk ratio (IRR) refrains from the risk occurring in the process of the potential faults ( $\Sigma Q R R)$ and the environmental impacts ( $\Sigma E R R)$ according to the Eq. 1.

$$
I R R=\sum_{i=1}^{n} Q R R i+\sum_{i=1}^{m} E R R i
$$

Quality risk ratio (QRR) reflects the level of occurrence probability of the particular fault, on the other hand, Environmental risk ratio (ERR) represents the occurrence probability of environmental influence of particular meaning.

In all cases, the risk ratio $(\mathrm{RR})$ covers the possibility of monitoring the process. Both Quality and Environmental risk ratio are dependent on importance of nonconformity/environmental impact (I), probability of occurrence of nonconformity/environmental impact $(\mathrm{O})$ as well as the effectiveness of monitoring of nonconformity/environmental impact (M), according to Eq. 2.

$$
R R_{i}=I_{i} \times O_{i} \times M_{i}
$$

Importance, probability of occurrence as well as the effectiveness of monitoring is expressed by the 1-10 value scale.

The value defined as Difficulty ratio (D) depends on the difficulty of assuring, in the process, the planned technological parameters and it is assessed with taking into consideration the human resources and the non-material resources ensured in the process. 


\section{RESULTS AND DISSCUSSION}

The technological process, being the subject of computer supported operational control aimed at fulfilment of the quality and environment requirements, is the process of the double-yokes stirrups dedicated to linking the elements of the roadway supports applied in the mining industry.

Each of the double-yoke stirrups is composed of top yoke, bottom yoke, two screws and two nuts. The analysed technological process covers the following: cutting the bottom yokes, cutting the sheets of the top yoke, bent of the top yoke and completing the stirrup. The feedstock for production of top and bottom yokes is $31 \mathrm{Mn} 4$ steel. After cutting the bottom yoke from the proper profile follows its piercing and front cutting. In case of the top yoke, the feedstock is as following: flat bar which is cut, pierced and front cut, and finally bent. The bent is performed after the prior heating. For screwing the yokes during completing are used special screws made of carburized, hardened and tempered steel as well as collar nuts. On the turned top yoke with the screws put inside, one puts the bottom yoke and tightens it first manually and finally - with the usage of the screw gun. The complete stirrup is characterised by featuring the trade mark, specification of variety as well as the year of production.

Acting according with the prepared methodology, firstly one has identified the operational criteria and features in the technological process of double-yokes stirrups preparation. Among the operational criteria, one has mentioned the following ones: force of pressure of the mechanical press during cutting and piercing process, force of cutting the front parts, time and temperature of heating, force of pressure the hydraulic press during the bent process and moment of tightening the screws' collar nut.

The defined operational criteria and features have been entered into the data base of the prepared software.

In succession, one has identified potential faults and environmental impacts in the process, their reasons and outcomes as well as the potential probabilities and importance of occurrence.

One has pointed that the operational criteria, different than the assumed, are most often accompanied by the following faults: improper shape and dimensions, roughness of surface, sharp edges on the front surfaces, asymmetry of holes placement, cracks and strains of the material in the place of bent, too small resistance to bents and cracks, strains and delamination, stiffness of friction joints or lack of proper carrying capacity, improper gauging of the material different than required.

Simultaneously, the process in question states the threat to the environment. It refrains from the following environmental influences: electro-magnetic field radiation, contamination of the waters by the industrial effluence, emission of noise, electric energy consumption and the feedstock intake. The exemplary calculations of the risk ratio value for the chosen faults and environmental impacts have been presented in Tables 1 and 2.

The key-operational criteria refraining from the appointed values of the operational criteria realisation Difficulty ratio (D) and the Integrated risk ratio (IRR) have been exposed to the assessment of stability and capability and have been regulated due to the needs with the usage of the developed computer application. 


\section{Table 1}

Comparison of the exemplary faults and assigned to them Quality risk ratio values (QRR) together with occurrence $(\mathrm{O})$, importance $(\mathrm{I})$ and monitoring $(\mathrm{M})$ in the stirrups' assembly operation

\begin{tabular}{|l|l|l|l|l|l|l|}
\hline \multicolumn{1}{|c|}{$\begin{array}{c}\text { Cause } \\
\text { of non-conformity }\end{array}$} & \multicolumn{1}{|c|}{$\begin{array}{c}\text { Non-conformity } \\
\text { (fault) }\end{array}$} & $\begin{array}{c}\text { Effect } \\
\text { of non-conformity }\end{array}$ & O & I & M & QRR \\
\hline $\begin{array}{l}\text { Too high values } \\
\text { of moment } \\
\text { of tightening } \\
\text { the nuts }\end{array}$ & $\begin{array}{l}\text { Stiffening } \\
\text { of friction joints, } \\
\text { permanent } \\
\text { deformation } \\
\text { of elements within } \\
\text { the stirrups }\end{array}$ & $\begin{array}{l}\text { Lowering of mine } \\
\text { roadway support's } \\
\text { capacity, worsening } \\
\text { of the workplace } \\
\text { safety }\end{array}$ & 4 & 8 & 10 & 320 \\
\cline { 2 - 7 } $\begin{array}{l}\text { Too low values } \\
\text { of moment of } \\
\text { tightening the nuts }\end{array}$ & $\begin{array}{l}\text { Inefficient capacity } \\
\text { of friction joint }\end{array}$ & & 4 & 8 & 10 & 320 \\
\hline
\end{tabular}

\section{Table 2}

Comparison of the exemplary environmental aspects and impacts, and assigned to them Environmental risk ratio values (ERR) together with occurrence $(\mathrm{O})$, importance (I) and monitoring $(\mathrm{M})$ in the top yoke heating operation

\begin{tabular}{|l|l|l|l|l|l|l|}
\hline $\begin{array}{c}\text { Cause of } \\
\text { environmental } \\
\text { aspect }\end{array}$ & $\begin{array}{c}\text { Environmental } \\
\text { aspect }\end{array}$ & \multicolumn{1}{|c|}{$\begin{array}{c}\text { Environmental } \\
\text { impact }\end{array}$} & O & I & M ERR \\
\hline $\begin{array}{l}\text { Yoke heating } \\
\text { before the bent }\end{array}$ & Energy intake & $\begin{array}{l}\text { Using-up } \\
\text { the natural sources }\end{array}$ & 10 & 5 & 1 & 50 \\
\hline $\begin{array}{l}\text { Induction heating } \\
\text { of yokes }\end{array}$ & $\begin{array}{l}\text { Electromagnetic } \\
\text { field emission }\end{array}$ & $\begin{array}{l}\text { Electromagnetic pollution } \\
\text { of the environment }\end{array}$ & 10 & 5 & 1 & 50 \\
\hline
\end{tabular}

Comparison of the $\mathrm{D}$ and IRR values for the analysed process together with the presentation of the key criteria undergoing the operational monitoring, has been presented in Table 3.

Table 3

Comparison of $\Sigma Q R R, \Sigma E R R$, IRR and D values for the stirrups' process together with the presentation of the key operational criteria

\begin{tabular}{|l|c|c|c|c|}
\hline Operational criteria & IQRR & IERR & IRR & D \\
\hline $\begin{array}{l}\text { Force of the hydraulic press' pressure and placement } \\
\text { during cutting and piercing the bottom yoke }\end{array}$ & 231 & 33 & 264 & 1 \\
\hline Force of cutting the bottom yoke & 45 & 71 & 116 & 1 \\
\hline $\begin{array}{l}\text { Force of the hydraulic press' pressure and placement } \\
\text { during cutting and piercing the top yoke }\end{array}$ & 231 & 33 & 264 & 1 \\
\hline Time and temperature of heating & 72 & $\underline{153}$ & 225 & 1 \\
\hline Force of the hydraulic press' pressure during bent & 219 & 63 & 282 & 1 \\
\hline Moment of tightening the collar nuts & $\underline{640}$ & 53 & $\underline{693}$ & $\underline{5}$ \\
\hline
\end{tabular}

Results of the integrated risk assessment and the difficulties of the process realisation have been applied within the scope of the operational monitoring of the operational criteria. 
The applied computer support module enabled defining the dependence between the particular criteria and the operational features as well as for calculating the risk ratio values of the particular incompatibilities (RR) based on the importance (I), occurrence $(\mathrm{O})$ and the monitoring effectiveness $(\mathrm{M})$. Basing on the values of the Integrated risk ratio and operational criteria realisation Difficulty ratio the module assured the control of the operational criteria of the key importance. The exemplary view of the window of the computer application used in the computer supported stirrups technological process has been shown in the Fig. 2.

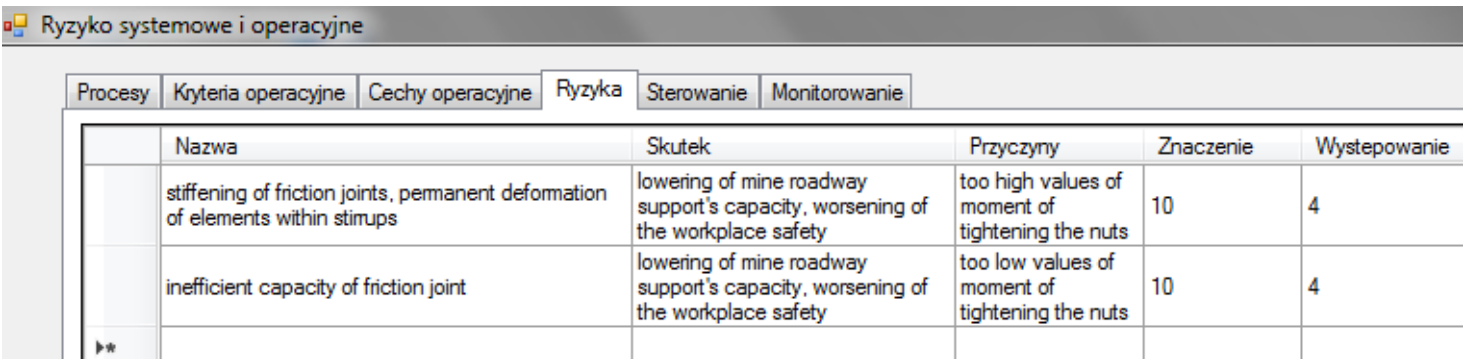

Fig. 2. View of the window of computer application module "Systemic and operational risk" used in the stirrups' process

\section{CONCLUSIONS}

The carried out research, with the application of the developed methodology, have allowed for identification in the stirrups' technological process the operational criteria of the key-importance.

As the meaningful criterion, one has pointed at - based on the difficulty of fulfilment this criteria $(D=5)$ as well as the risk refraining from the presence of the potential failures and environmental influence (IRR $=693$ ) - moment of tightening the collar nuts during the operation of assembling the stirrups. High value of Quality risk ratio $(\Sigma Q R R=640)$ has refrained from application of too high or low moments of tightening the nuts on the screws, which in turn resulted in stiffing the friction joints and permanent deformation of the stirrups' elements or insufficient capacity of the stirrups leading to lowering capacity of the building site and worsening workplace safety. Low value of the Environmental risk ratio $(\Sigma E R R=53)$ was caused by electric energy and other media consumption, generating the steel waste and other ones, as well as the emission of noise.

As the key-issue, one has also described the parameters of top yoke heating. Such classification has been chosen due to the high Environmental risk ratio ( $\Sigma E R R=153$ ) refraining especially from the electric energy consumption and the electromagnetic field emission.

The carried out research have also confirmed that the development of the tools for the key-aspects identification is effective in the analysed process of the double-yokes stirrups. The developed and worked out computer application enables both: integration of the key-parameters as well as steering these parameters and it facilitates the operational monitoring and supervision in a complex way. Therefore, one can assume that it is possible to take advantage of both: methodology of identification as well as computer support, in the similar processes which both, due to their meaning towards the safety of the produced goods as well as the environmental threats, should undergo constant supervision. 


\section{REFERENCES}

Asif, M., Fisscher, A. M., de Bruijn, E. J., Pagell, M., 2010. An examination of strategies employed for the integration of management systems. The TQM Journal, 22(6), 648-669, DOI: 10.1108/17542731011085320.

Bernardo, M., Casadesus, M., Karapetrovic, S., Heras, I., 2009. How integrated are environmental, quality and other standardized management systems? Journal of Cleaner Production, 17(8), 742-750, DOI: 10.1016/j.jclepro.2008.11.003.

Bernardo, M., Casadesus, M., Karapetrovic, S., 2011. Are methods used to integrate standardized management systems a conditioning factor of the level of integration. An empirical study, International Journal for Quality Research, 5(3), 213-222.

Brodny, J., 2013. Analysis of stirrups impact on the parameters of friction joint operation. In: Biały, W., Kuboszek, A. (Eds.), Support systems in production engineering. P.A. Nova, Gliwice, Poland.

Brodny, J., 2015. Tests of stirrups applied in mining yielding support of dog headings. Silesian Technical University, Gliwice, Poland.

Brodny, J., 2011. Tests of friction joints in mining yielding supports under dynamic load. Archives of Mining Sciences, 56, 303-318.

Esquer-Peralta, J., Velazquez, L., Munguia, N., 2008. Perceptions of core elements for sustainability management systems (SMS). Management Decision, 46(7), 1027-1038, DOI: 10.1108/00251740810890195.

Jørgensen, T., Remmen, A., Mellado, M. D., 2006. Integrated management systems three different levels of integration. Journal of Cleaner Production, 14(8), 713-722, DOI: 10.1016/j.jclepro.2005.04.005.

Karapetrovic, S., Casadesus, M., Heras, I., 2006. Dynamics and integration of standardized management systems: an empirical study. Documenta Universitaria, GITASP 1, Girona, Spain.

Karapetrovic, S., Casadesus, M., Heras, I., 2010. Analysis of integration within the standards-based integrated management systems. Proceedings of $4^{\text {th }}$ International Quality Conference, Kragujevac, Serbia, 11-21.

Karkoszka, T., 2016. Factors influencing the requirements fulfillment in the zinc coating processes. Metalurgija, 55, 765-768.

Karkoszka, T., 2017. Operational control with application of the risk analysis in the integrated management system of technological process. Silesian Technical University, Gliwice, Poland.

Labodova, A., 2004. Implementing integrated management systems using a risk analysis based approach. Journal of Cleaner Production, 12(6), 571-580, DOI: 10.1016/j.jclepro.2003.08.008.

Rocha, M., Searcy, C., Karapetrovic, S., 2007. Integrating sustainable development into existing management systems. Total Quality Management \& Business Excellence, 18(1/2), 83-92, DOI: 10.1080/14783360601051594.

Simon, A., Karapetrovic, S., Casadesus, M., 2011. Integrating management systems: A dynamic study of Spanish firms. Proceedings of the $5^{\text {th }}$ International Conference on Industrial Engineering and Industrial Management, Cartagena, Spain, 164-174.

ISO Survey, 2017. www.iso.org/iso/iso-survey.

ISO 9001, 2015. Quality management systems - Requirements. ISO, Genève, Switzerland.

ISO 14001, 2015. Environmental management systems - Requirements with guidance for use. ISO, Genève, Switzerland. 